\title{
Microstructure and In Situ Observations of Undercooling for Nucleation of $\beta$-Sn Relevant to Lead-Free Solder Alloys
}

\begin{abstract}
JOHN W. ELMER, ${ }^{1,3}$ ELIOT D. SPECHT, ${ }^{2}$ and MUKUL KUMAR ${ }^{1}$
1.-Lawrence Livermore National Laboratory, Livermore, CA 94550, USA. 2.-Oak Ridge

National Laboratory, Oak Ridge, TN, USA. 3.—e-mail: elmer1@llnl.gov

Difficult nucleation of $\beta$-Sn during solidification of tin and tin-based lead-free solder alloys can result in high degrees of undercooling of the liquid prior to solidification. The undercooling can produce solder joints with large grains, anisotropic behavior, and undesirable mechanical properties. This paper describes our examination of the amount of undercooling of tin on both graphite (non-wetting) and copper (wetting) surfaces using in situ x-ray diffraction. The microstructure was further characterized by optical microscopy, scanning electron microscopy, and electron backscattering diffraction imaging microscopy. Undercoolings as high as $61^{\circ} \mathrm{C}$ were observed for Sn solidified on graphite, while lower undercoolings, up to $30^{\circ} \mathrm{C}$, were observed for Sn solidified on copper. The microstructure of the high purity Sn sample solidified on graphite showed very few grains in the cross-section, while the commercially pure Sn sample solidified with only one grain and was twinned. Tin solidified on copper contained significant amounts of copper in the tin, intermetallic phase formation at the interface, and a eutectic microstructure.
\end{abstract}

Key words: In situ x-ray diffraction, solidification, nucleation, undercooling, twinning, grain boundaries, tin, lead-free solders, cooling rate, microstructure, wetting

\section{INTRODUCTION}

Tin-based alloys represent the vast majority of solders being used as lead-free alternatives to traditional solders. These alloys are finding numerous application in everything from consumer electronics to high reliability constituents of military and aerospace components. This departure from leadcontaining traditional alloys is being driven not only by legislation to remove toxic metals, such as lead and cadmium, from solder and brazing alloys, ${ }^{1,2}$ but also by a need to produce higher quality components more efficiently. Although cadmium has largely been eliminated from brazing alloys by suitable alternatives, lead has not been completely eliminated from solder alloys, due to its wide-ranging application in the microelectronics industry.

Many of the lead-free replacement solders under consideration are based on the $\mathrm{Sn}-\mathrm{Ag}$ eutectic,

(Received August 8, 2009; accepted January 6, 2010;

published online February 2, 2010) modified with small amounts of $\mathrm{Cu}, \mathrm{Bi}$, or $\mathrm{Sb}$ to improve strength and creep resistance while maintaining a melting point close to that of the $\mathrm{Sn}-\mathrm{Ag}$ eutectic of $217^{\circ} \mathrm{C} .^{3}$ Other lead-free solders deviate considerably from the Sn-Ag eutectic in attempts to improve properties or intentionally change the liquidus and solidus temperatures for one reason or another, but nearly all are Sn-based alloys containing $90 \% \mathrm{Sn}$ or more. The prevalence of $\mathrm{Sn}$ in lead-free solders and its increasing importance to the electronics industry requires that significant resources be devoted to our understanding of the fundamental properties of tin as it relates to all aspects of soldering.

Tin is unusual in that it is one of only two elemental metals with a tetragonal crystal structure and undergoes a low temperature phase transformation from $\alpha$ [face-centered-cubic (fcc)] which is an undesired phase of tin to $\beta$ [body centered tetragonal (bct)] at $13.2^{\circ} \mathrm{C}$ and above. In addition, during solidification, the solid $\beta$-Sn phase is difficult to nucleate from the liquid, which results in observed 
undercoolings of over $100^{\circ} \mathrm{C}$ below its melting point under very carefully controlled conditions, ${ }^{4,5}$ and the amount of undercooling was shown to increase monotonically with decreasing solder ball size. ${ }^{6}$ Even under normal processing conditions at moderately low cooling rates, undercoolings of up to $40^{\circ} \mathrm{C}$ have been observed..$^{5,7}$ The undercooling results in very fast growing $\beta$-Sn dendrites and produces a textured microstructure with few individual grains in the solder joint. ${ }^{8}$ Under these conditions, the anisotropic nature of tetragonal $\beta$-Sn is not randomized, leading to mechanical weakness of the joint, particularly where thermal fatigue is a concern. ${ }^{9-11}$ The unusual solidification behavior of pure tin continues into the Sn-rich solder alloys, which results in undercoolings of $25-40^{\circ} \mathrm{C} .{ }^{7,12}$ The associated formation of nonequilibrium microstructures is almost always detrimental to the mechanical properties of the resulting solder joint. Delayed nucleation of $\beta$-Sn during solidification is known to result in higher fractions of primary, or primary-like, constituents, large $\beta$-Sn dendrites, large grains, reduced amounts of eutectic, higher amounts of microconstituents, and undesired morphologies of the intermetallic compounds (e.g., large $\mathrm{Ag}_{3} \mathrm{Sn}$ plates or long $\mathrm{Cu}_{6} \mathrm{Sn}_{5}$ needles) which are often hard and brittle. ${ }^{12,13}$

This paper details our investigation of the properties of tin melted and solidified on different substrates, using in situ x-ray diffraction to observe directly the amount of undercooling prior to solidification to $\beta$-Sn. The results were combined with microstructural characterization of the solidified tin samples to show the influence of graphite (nonwetting) and copper substrates on the final microstructure.

\section{EXPERIMENTAL PROCEDURES}

In situ x-ray diffraction experiments were performed at the Advanced Photon Source (APS) using a setup similar to the one used previously to study phase transformation of metals under controlled heating and cooling conditions. ${ }^{14-18}$ These experiments were performed by the rapid heating and cooling of samples under controlled conditions while simultaneous x-ray diffraction was performed, using the UNICAT beam line BM-33-C at the APS with a $29.1 \mathrm{keV}$ x-ray beam from a ring current of $100 \mathrm{~mA}$. This energy is just below the Sn k- $\alpha$ absorption edge of $29.2 \mathrm{keV}$ and allowed deep penetration of the x-rays into the Sn-rich solder samples. This beam line was set up with a water-cooled $\mathrm{Si}$ (111) monochromator, and the beam was focused and sized to approximately $2 \mathrm{~mm}$ wide by $0.5 \mathrm{~mm}$ high by the use of a dynamically bent $\mathrm{Si}$ crystal and collimator slits. A schematic illustration of the experimental setup is shown in Fig. 1, and additional details about these x-ray diffraction experiments have been provided elsewhere for in situ measurements of phase transformations, ${ }^{15,16}$ diffusion, ${ }^{17}$ and stress relaxation. ${ }^{18}$

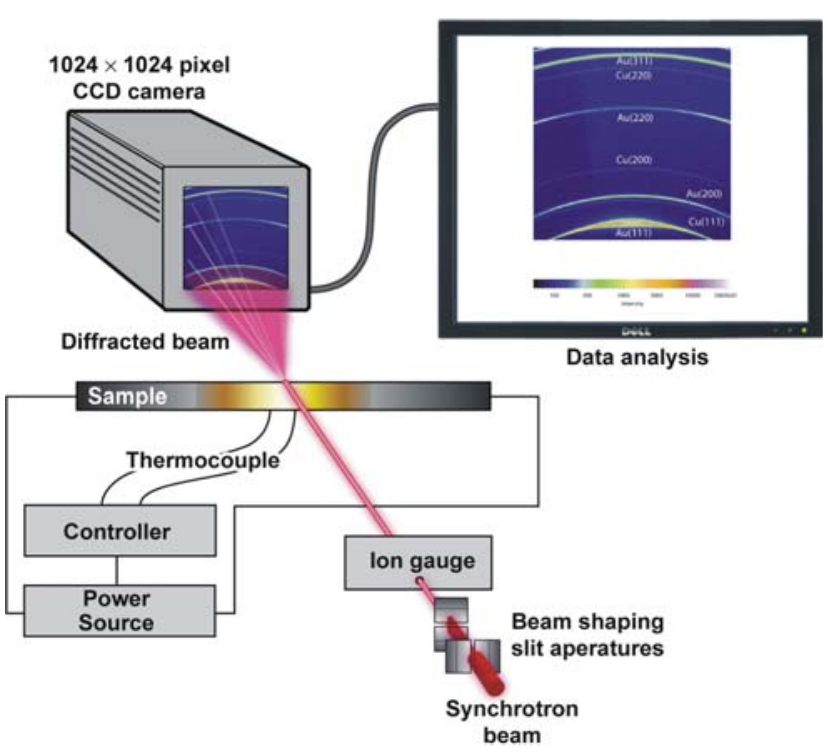

Fig. 1. Schematic of the synchrotron setup for direct observations of materials being resistively heated. The sample is enclosed in an environmental chamber (not shown) to protect it from oxidation.

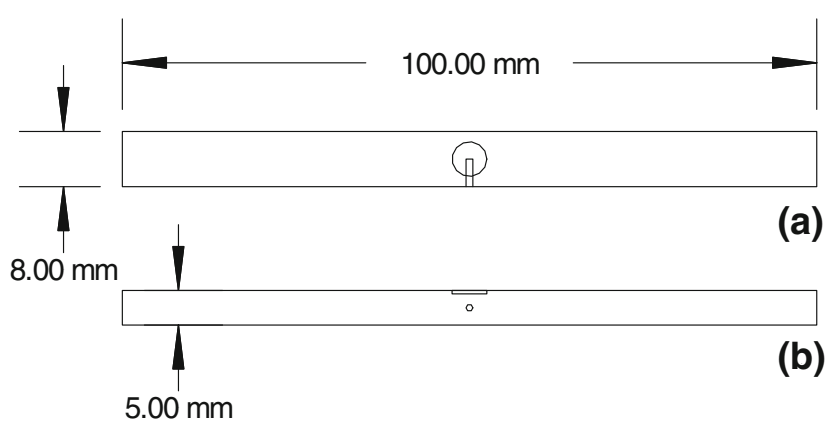

Fig. 2. Graphite sample holder design (a) top view, (b) side view. The circular disk sample is placed in the hole (5.00 $\mathrm{mm}$ diameter) in the top center of the sample holder. A small hole is drilled for the thermocouple to be inserted directly below the center of the solder disk.

The new experiments on tin-based solder alloys required a modification to the previous setup, since the samples would be molten during a portion of time. To do this, a graphite sample holder was designed for resistive heating, which, in turn, heated the tin alloys and metal substrates inside. A graphite sample holder was chosen because it does not react with tin and is easily heated by resistive methods. The sample holder design is shown in Fig. 2 and measured $100 \mathrm{~mm} \times 8 \mathrm{~mm} \times 5 \mathrm{~mm}$, with a $5 \mathrm{~mm}$-diameter circular disk machined out of the top surface to hold the metal samples. Different hole depths were machined into the sample holder, allowing different combinations of solder alloy thicknesses and substrates to be used. A $1 \mathrm{~mm}-$ diameter hole was drilled into the side of the graphite sample holder to allow a type $\mathrm{K}$ thermocouple to be placed directly below the center of the solder disk. Silver-loaded thermally conductive grease was placed in the hole to insure good thermal 

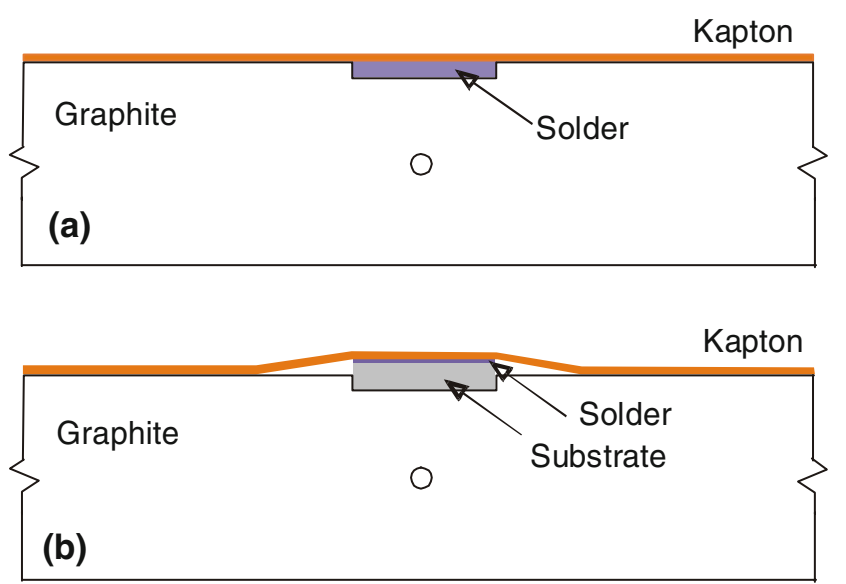

Fig. 3. Schematic side-view illustrations of the graphite sample holder and solder alloy configuration for (a) the type-1 experiment, where only the solder is melted and solidified in the graphite sample holder, and (b) the type-2 experiment, where a thin solder layer is held in contact with a substrate.

contact between the thermocouple and the graphite. The loaded sample holder was placed into the watercooled grips of the heating stage with an $\sim 5^{\circ}$ tilt to the axis of the $\mathrm{x}$-ray beam and aligned so that the $2 \mathrm{~mm} \times 0.5 \mathrm{~mm}$ beam was centered on the sample. An environmental chamber was then placed over the sample and evacuated with a turbo-molecular pump to prevent oxidation of the samples during the in situ experiments.

Two basic types of experiments were performed. In the first, Sn was heated to and from its melting point at different rates so that phase transformations could be observed as a function of temperature and time. In these experiments the tin sample was loaded directly into the graphite sample holder with its surface at the same level as that of the graphite. A Kapton strip measuring $100 \mathrm{~mm} \times 8 \mathrm{~mm} \times$ $0.100 \mathrm{~mm}$ was then placed over the top of the sample holder to hold the sample in place. Figure 3a illustrates this setup where the Kapton layer contains the molten tin and is thin enough to allow x-rays to pass through it. In addition, the Kapton strip does not react with the solder and keeps the surface flat by preventing the liquid solder from balling at its center point. In the second type of experiment the tin was placed on a $\mathrm{Cu}$ substrate so that the $\mathrm{Sn}-\mathrm{Cu}$ reactions could be observed. Figure $3 \mathrm{~b}$ is a schematic illustration of the solder and substrate combination, with the thin Kapton layer stretched over the top to keep the tin layer contained and flat.

The alloys used in the experiments consisted of high purity tin (99.999\%Sn, Alfa Aesar no. 38538), commercial purity tin $(99.8 \% \mathrm{Sn}$, Alfa Aesar no. 43233), high purity graphite, and high purity copper substrates. Table I lists the alloys and the thicknesses of each sample. Since tin readily oxidizes at room temperature, there is an oxide layer on the initial samples that prohibit them from
Table I. Tin and tin-silver-copper solder alloys and substrates used in the experiments

\begin{tabular}{|c|c|c|c|}
\hline $\begin{array}{l}\text { Alloy } \\
\text { (wt.\%) }\end{array}$ & $\begin{array}{c}\text { Composition } \\
(\mathbf{w t .} \%)\end{array}$ & $\begin{array}{c}\text { Thickness } \\
(\mu \mathrm{m})\end{array}$ & $\underset{\left({ }^{\circ} \mathbf{C}\right)^{\mathrm{a}}}{\boldsymbol{T}_{\mathbf{m}}}$ \\
\hline Sn, commercial purity & $99.8 \mathrm{Sn}$ & 250 & 232 \\
\hline Sn, high purity & $99.999 \mathrm{Sn}$ & 50 & 232 \\
\hline $\mathrm{Cu}$ substrate & $99.95 \mathrm{Cu}$ & 250 & 1083 \\
\hline $\begin{array}{l}\text { Graphite substrate } \\
\text { (ISO } 63 \text { fine grained) }\end{array}$ & $99.9 \mathrm{C}$ & 5000 & 3642 \\
\hline
\end{tabular}

${ }^{\mathrm{a}} T_{\mathrm{m}}$ corresponds to the equilibrium melting temperature.

wetting onto the copper substrate and flowing onto the graphite substrate. To reduce the surface oxide layer we dipped the tin samples into a rosin-based mildly active (Indium Corporation RMA flux no. 5) liquid flux prior to assembling them into the graphite sample holder. This flux is reported to contain $40-50 \%$ rosin mixture, 30-40\% isopropyl alcohol, 10-30\% methyl ethyl ketone, and 1-2\% proprietary ingredients, by weight.

The solidified solder samples were further characterized after the in situ x-ray diffraction experiments by optical light microscopy, scanning electron microscopy (SEM), and electron backscattering diffraction (EBSD) imaging. ${ }^{19}$ We carefully prepared the samples for microstructural characterization by first mounting the solder disk in two-part epoxy or silver-loaded conductive epoxy. After the samples had been hardened, we gently hand-sanded them to their $1 / 4$ radius location to reveal the cross-section of the solder disk, using successive grit sizes of silicon carbide paper. The samples were then polished with $3 \mu \mathrm{m}$ then $1 \mu \mathrm{m}$ diamond paste on an automatic polishing wheel. Optical microscopy was performed on the Sn samples solidified on graphite in the as-polished condition, while the Sn samples solidified on copper were etched prior to examination. The SEM and EBSD analyses were performed on polished samples with an EBSD detector mounted on a Philips XL30S FEG scanning electron microscope. The grain orientations were mapped and analyzed to enable us to determine the orientation relationships in the solidified Sn samples.

\section{RESULTS}

\section{Tin on Graphite Substrates}

The first set of experiments consisted of the melting and solidifying of high purity and commercial purity tin on a graphite surface with the experimental setup schematically illustrated in Fig. 3a. Since graphite and the Kapton strip do not react with tin, the tin melts and solidifies in such a way that any heterogeneous nucleation effects induced by the substrate are minimized. One would therefore expect that the amount of undercooling of the liquid tin during solidification would likely be 


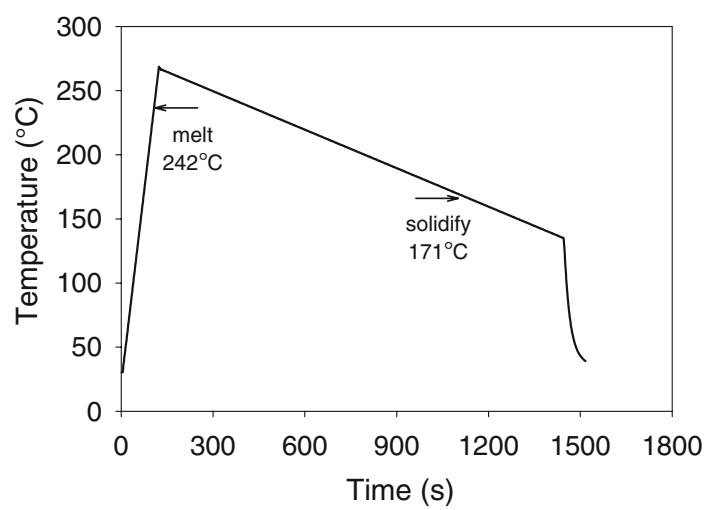

Fig. 4. Time-temperature profile for the heating and cooling of the commercially pure $\mathrm{Sn}$ sample on graphite. The heating rate was $2{ }^{\circ} \mathrm{C} / \mathrm{s}$ and the cooling rate was $0.1^{\circ} \mathrm{C} / \mathrm{s}$ over the controlled portion of the cooling curve.

larger than if the tin were in contact with a reacting substrate such as copper. The tin samples were heated at a rate of $2{ }^{\circ} \mathrm{C} / \mathrm{s}$, held at the peak temperature of $257^{\circ} \mathrm{C}$ for $1 \mathrm{~s}$, and then cooled at rates between $0.1{ }^{\circ} \mathrm{C} / \mathrm{s}$ and $5{ }^{\circ} \mathrm{C} / \mathrm{s}$. Thus, the total time spent above the liquidus temperature of tin $\left(232^{\circ} \mathrm{C}\right)$ was in excess of $20 \mathrm{~s}$ in all cases, which was sufficient for the tin to melt and flow to a smaller diameter disk shape under the constraining force of the Kapton cover. A time-temperature profile for one of the commercial purity Sn samples cooled at a slow rate of $0.1^{\circ} \mathrm{C} / \mathrm{s}$ is shown in Fig. 4, as measured by the thermocouple directly below the sample. The temperature profile was controlled down to approximately $125^{\circ} \mathrm{C}$ and free cooled during the remainder of the experiment.

While the sample was being heated and cooled, $\mathrm{x}$ ray diffraction patterns were taken and later analyzed to enable us to determine when $\beta$-Sn first appeared, which would indicate the onset of solidification. Figure 5 shows one of the initial diffraction patterns for the commercial purity $\mathrm{Sn}$ at room temperature. There are eight Sn diffraction peaks that appear in the x-ray diffraction window between $1.4 \AA$ and $3.0 \AA$. Strong graphite peaks appear at higher $d$-spacings (not shown). The two most prominent Sn peaks are the Sn (200) located at $2.916 \AA$, and the Sn (101) located at $2.793 \AA$, as calculated from the lattice parameters of bct white Sn of $a=5.8313 \AA$ and $c=3.1815 \AA{ }^{20}$ Note that texturing of the thin foil alters the diffraction intensities of the peaks, and, in this case, has resulted in an increase in the $\mathrm{Sn}$ (101) relative to the Sn (200) from the ideal powder diffraction condition. In addition, very few grains in the solidified solder samples result in even more dramatic changes in these intensities, including the disappearance of many of the peaks, as will be seen later.

Figure 6 shows the results from one of the in situ $\mathrm{x}$-ray diffraction runs where the commercial purity tin $(99.8 \% \mathrm{Sn})$ was melted and solidified in the graphite sample holder following the time-temperature

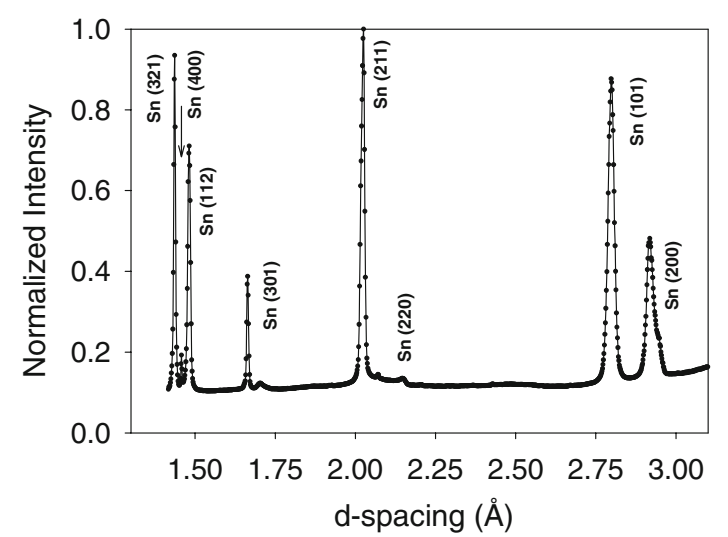

Fig. 5. Initial diffraction pattern of commercial purity Sn showing the eight $\mathrm{Sn}$ peaks in the diffraction window. Texture of the thin foil results in non-ideal peak intensities.

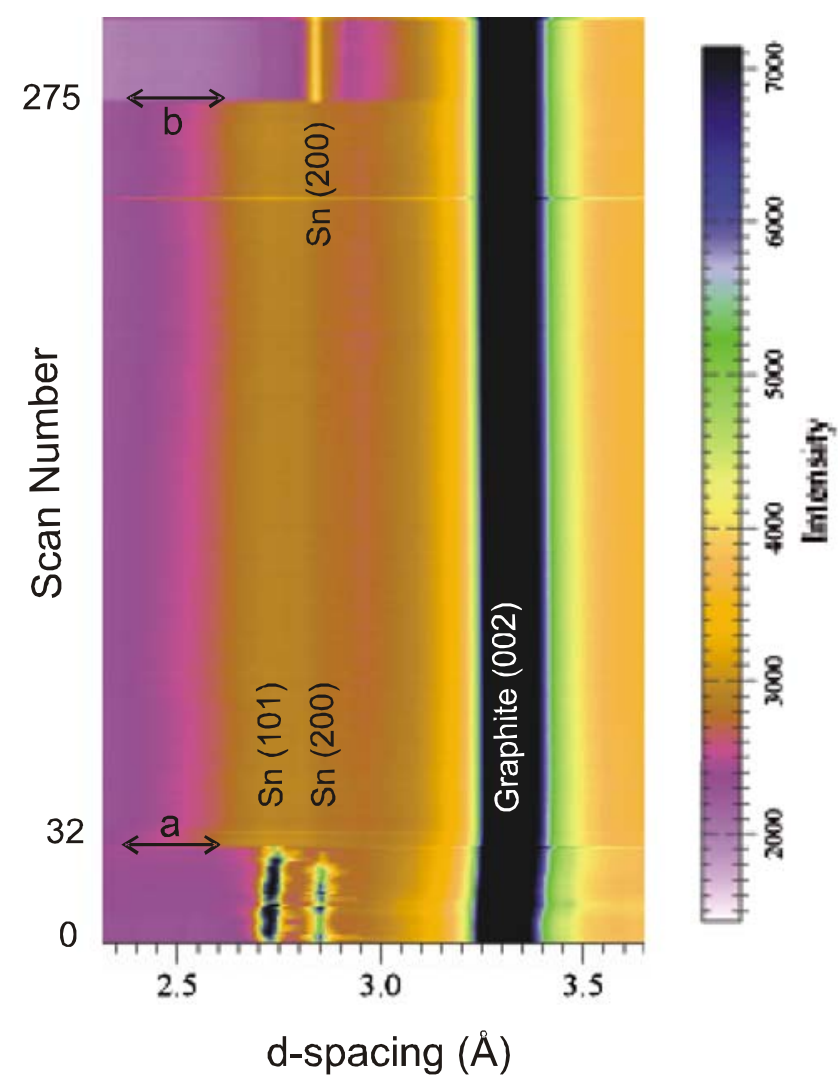

Fig. 6. In situ x-ray diffraction patterns for commercially pure Sn on graphite cooled at $0.1^{\circ} \mathrm{C} / \mathrm{s}$, zoomed in to show the two major diffraction peaks of tin: $S n(101)$ at $2.75 \AA$ and $S n(200)$ at $2.85 \AA$. The $y$-axis sequentially plots 300 diffraction patterns throughout the experiment. Heating begins at scan 0 , melting is complete at ' $a$ ', and solidification begins and ends quickly at 'b', leaving only the Sn (200) peak diffracting during cooling.

profile shown in Fig. 4. This result shows the sequential diffraction patterns, plotted as $d$-spacing on the $x$-axis versus x-ray scan number along the $y$-axis, where each $\mathrm{x}$-ray scan was taken at a $3 \mathrm{~s}$ interval. The x-ray diffraction patterns are plotted 
in pseudocolor format, indicated by the adjacent intensity scale.

The initial diffraction pattern, scan 0 , corresponds to the tin disk sitting on the graphite sample holder prior to the heating of the sample. A wide graphite diffraction peak (002) appears at $d \sim 3.3 \AA$, and two Sn peaks appear at $2.75 \AA \mathrm{Sn}$ (101), and $2.85 \AA \mathrm{Sn}$ (200) in this figure. Once heating begins, the $\mathrm{Sn}$ and graphite peaks move to higher $d$-spacings due to lattice expansion effects, and the Sn melts at frame 32. Complete melting of the sample is characterized by the disappearance of the Sn peaks and the appearance of a more diffuse background characteristic of liquid Sn, while the graphite peak remains essentially constant throughout the experiment. Solidification begins and finishes at frame 275, where the Sn (200) peak reappears and remains throughout the remainder of the experiment. The absence of the Sn (101) peak on solidification indicates that the sample has few diffracting grains, as discussed below. Owing to these poor grain statistics, freezing cannot be reliably detected by the appearance of Bragg reflections from the solid; the disappearance of the diffuse scattering from the liquid is a more robust indicator of freezing.

Analysis of the thermal profile for the sample indicated that it melted at $242^{\circ} \mathrm{C}$, which was $10^{\circ} \mathrm{C}$ higher than the equilibrium value. This apparent superheating was related to several possible factors, including the temperature resolution of the experiment. With a heating rate of $2{ }^{\circ} \mathrm{C} / \mathrm{s}$, and a sampling rate of one sample every $3 \mathrm{~s}$, there was an up to $6^{\circ} \mathrm{C}$ uncertainty in the data, and the remaining difference was related to the accuracy of the thermocouple and temperature gradients in the sample. During cooling, solidification was indicated to have occurred at a temperature of $171^{\circ} \mathrm{C}$, which was $61^{\circ} \mathrm{C}$ below its equilibrium value. This large degree of undercooling was consistent with what had been observed by others for tin solidified under careful conditions in contact with non-reacting substrates. ${ }^{4,5}$ We expected that the measurement of freezing temperature would be more accurate than that of melting temperature, for two reasons: the sample was cooled more slowly than it was heated, giving finer temperature resolution, and the graphite sample holder was in better thermal contact with the cooling liquid Sn than with the solid Sn disk on heating.

Two other runs were made with commercially pure Sn at cooling rates of $1{ }^{\circ} \mathrm{C} / \mathrm{s}$ and $5{ }^{\circ} \mathrm{C} / \mathrm{s}$. These results are summarized in Table II and showed that the average undercooling of the commercially pure Sn samples was $55^{\circ} \mathrm{C}$, which was slightly higher than that found in recently reported experiments using differential scanning calorimetry (DSC) for Sn samples solidified on an $\mathrm{Al}$ substrate. ${ }^{7}$ Note that there was no obvious trend between cooling rate and undercooling for the range of cooling rates studied here. Additional samples need to be run to enable us to obtain a statistical variation in the undercooling as a function of cooling rate, and these experiments are planned as future work.

Similar results were obtained for the high purity Sn sample $(99.999 \% \mathrm{Sn})$ on the graphite substrate; however, the measured undercooling was not as large. In the case of high purity $\mathrm{Sn}$, the sample melted at $246^{\circ} \mathrm{C}$ and solidified at $212^{\circ} \mathrm{C}$. This resulted in a $20^{\circ} \mathrm{C}$ undercooling below the melting point of pure $\mathrm{Sn}\left(232^{\circ} \mathrm{C}\right)$. This rather low undercooling was unexpected, and additional experiments are planned as future work to gather statistics on the undercooling of high purity Sn.

The measured undercooling in both the high purity and commercial purity Sn samples was high enough to confirm that nucleation of $\beta$-Sn is difficult and that there is likely an adverse effect on the microstructure. To take a closer look at this, we characterized the microstructure of the two solidified tin disks, using optical light microscopy on metallographically sectioned and polished samples. Figure $7 \mathrm{a}$ shows the microstructure near the halfradius location of the solidified high purity Sn disk, where the microstructure is characterized by having very few grains. This sample was originally in the form of a $5 \mathrm{~mm}$-diameter disk, $50 \mu \mathrm{m}$ thick, and, after solidification, it had become thicker. Bumps in

Table II. Summary of measured melt and solidification temperatures and undercooling $(\Delta T)$ of the tin on graphite and copper substrates

\begin{tabular}{|c|c|c|c|c|c|}
\hline Alloy & Substrate & Cooling Rate $\left({ }^{\circ} \mathrm{C} / \mathrm{s}\right)$ & Melt $\left({ }^{\circ} \mathbf{C}\right)$ & Solidify $\left({ }^{\circ} \mathbf{C}\right)$ & $\Delta T=\left(T_{m}^{\circ}-T_{s}\right)\left({ }^{\circ} C\right)^{\mathrm{a}}$ \\
\hline Sn 99.999 & Graphite & 2 & 245.9 & 212.0 & 20.0 \\
\hline \multirow[t]{3}{*}{ Sn 99.8} & Graphite & 5 & 255.6 & 186.4 & 45.6 \\
\hline & & 1 & 255.7 & 172.2 & 59.8 \\
\hline & & 0.1 & 242.0 & 171.1 & 60.9 \\
\hline \multirow[t]{3}{*}{ Sn 99.99} & Copper & 4 & 223.9 & 201.6 & 25.4 \\
\hline & & 0.5 & 219.3 & 204.5 & 22.5 \\
\hline & & 0.05 & 218.0 & 196.9 & 30.1 \\
\hline
\end{tabular}

${ }^{\mathrm{a}} T_{\mathrm{m}}^{\circ}$ refers to the melting point of pure $\mathrm{Sn}\left(232^{\circ} \mathrm{C}\right)$ for the samples solidified on graphite and the $\mathrm{Sn}$-Cu eutectic $\left(227^{\circ} \mathrm{C}\right)$ for the samples solidified on $\mathrm{Cu}$. The heating rate was $2{ }^{\circ} \mathrm{C} / \mathrm{s}$ on all samples. 
(a)

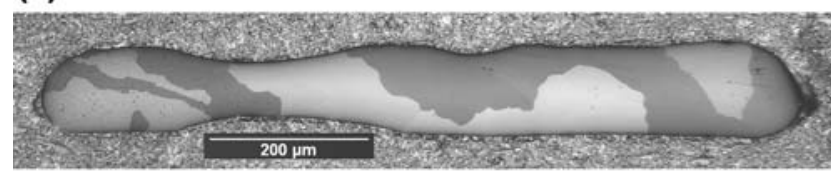

(b)

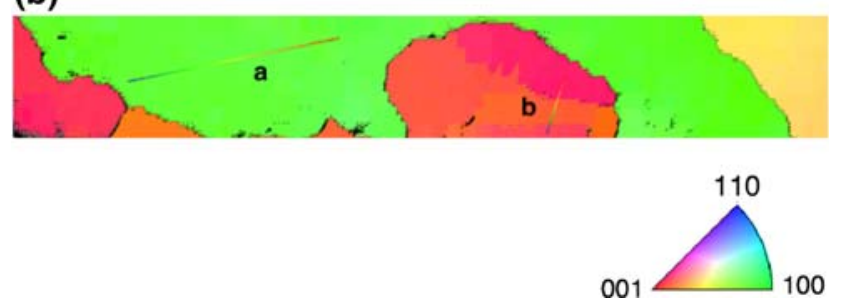

Fig. 7. (a) Optical light microscopy cross-section through the high purity tin $(99.999 \% \mathrm{Sn})$ sample solidified on graphite in the as-polished condition using polarized light, and (b) EBSD map of a portion section of the sample to the right side of center. Sample cooled at $2{ }^{\circ} \mathrm{C} / \mathrm{s}$.

the surface correspond to the flux trapped between the $\mathrm{Sn}$ and the substrate. The grain boundaries are clearly defined by light and dark contrast in the polarized light, and are wavy in appearance.

To understand better the microstructures of the solidified tin samples, we utilized EBSD to characterize the nature of the grain boundaries and other features. Figure $7 \mathrm{~b}$ shows an EBSD inverse pole image for the high purity Sn sample solidified on graphite, which contained only a few grains in the cross-section. These results show the same large angle grain boundaries that were observed by optical microscopy, but they also indicate substructure within these grains. The substructure is indicated by changes in the color shading and are particularly evident in the grain marked ' $b$ ', which is near the (001) corner of the stereographic triangle. The misorientation within the grains of the microstructure is shown in Fig. 8a, for a grain that showed only slight variations in misorientation, and in Fig. 8b, for a grain that showed a larger variation in misorientation. The misorientation plot shown in Fig. 8a corresponds to the scan marked 'a' in the EBSD map shown in Fig. 7b and plots the misorientation as both a point-to-point trace and a cumulative point-to-origin trace. The misorientation in this sample was small, showing point-to-point variations on the order of $1^{\circ}$ or less, and the cumulative misorientation was only $2^{\circ}$ over the $120 \mu \mathrm{m}$ trace. For the EBSD scan marked 'b' in Fig. 7b, larger misorientations are present, up to $4^{\circ}$, with point-to-point variations occurring on the $5 \mu \mathrm{m}$ scale.

The microstructures of the commercial purity Sn samples solidified on graphite are shown in Fig. 9 for solidification rates of $0.1{ }^{\circ} \mathrm{C} / \mathrm{s}$ and $1{ }^{\circ} \mathrm{C} / \mathrm{s}$. These microstructures were considerably different from those of the high purity Sn samples. In Fig. 9a the microstructure of the more slowly cooled commercially pure Sn sample is completely featureless,
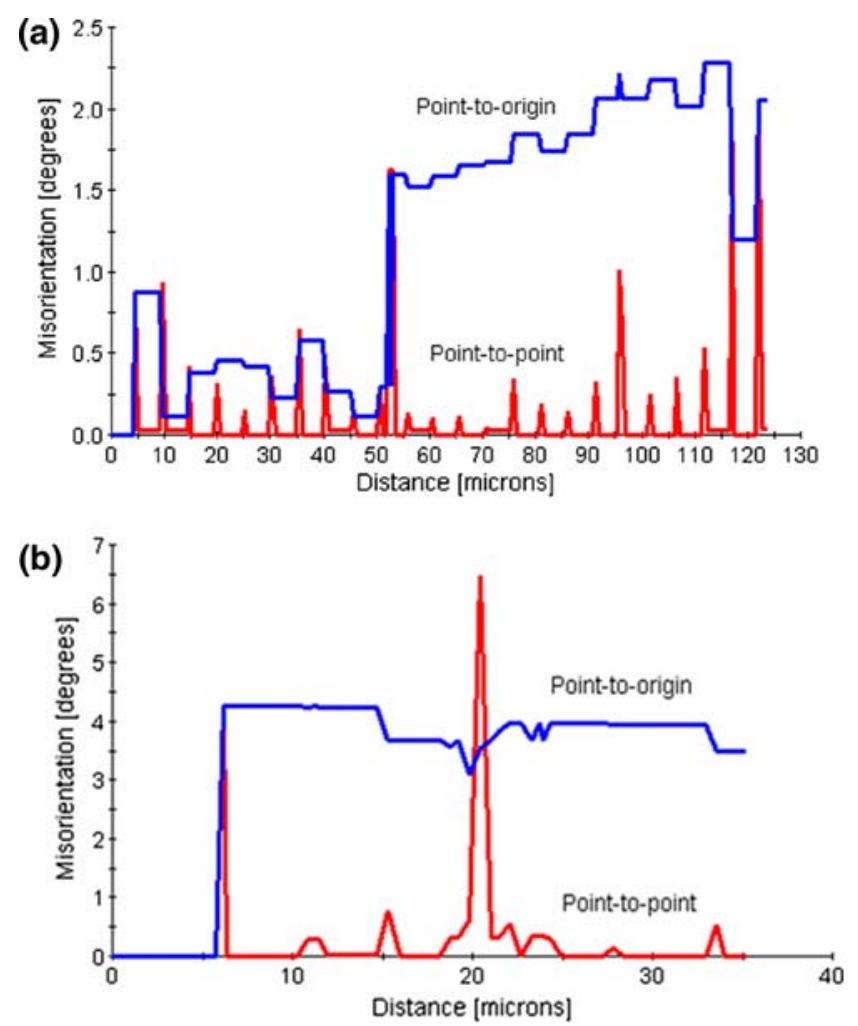

Fig. 8. EBSD scans showing misorientation in the high purity Sn solidified on the graphite surface shown in the previous figure for (a) a single grain across the scan marked 'a' in Fig 7b, (b) across a subgrain boundary 'b' in Fig. $7 b$.
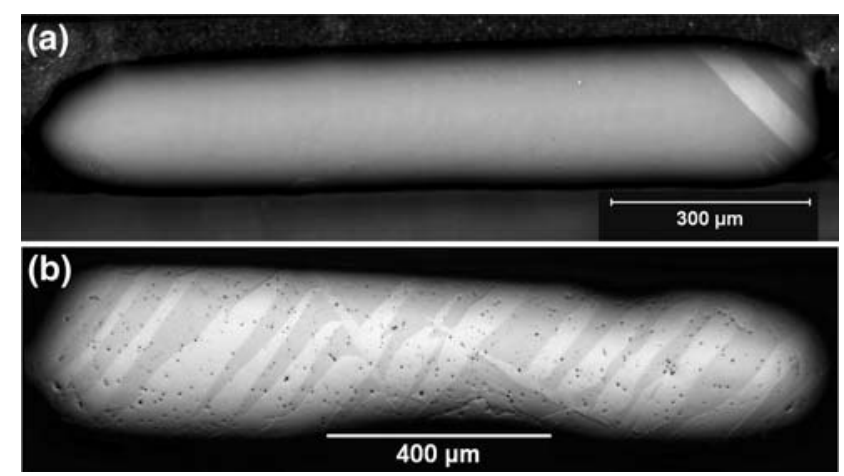

Fig. 9. Optical light microscopy of the cross-section through the commercially pure tin $(99.8 \% \mathrm{Sn})$ samples in the as-polished condition using polarized light. (a) solidified at $0.1{ }^{\circ} \mathrm{C} / \mathrm{s}$ and (b) solidified at $1{ }^{\circ} \mathrm{C} / \mathrm{s}$.

except for what appears to be several twins in the upper right hand corner. In Fig. 9b the microstructure of the more rapidly cooled sample is still different, having a candy-striped appearance with alternating light and dark bands that have an angular appearance running completely across the sample. In both cases the commercially pure Sn samples are believed to have solidified as one grain 


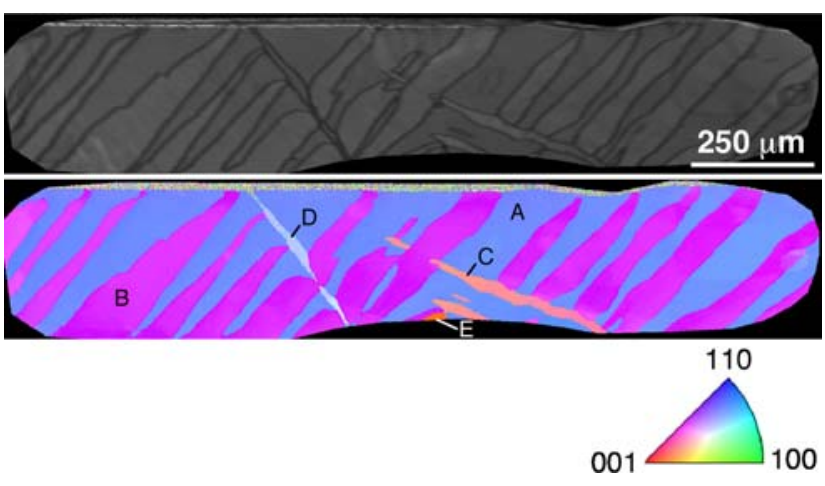

Fig. 10. Results of the EBSD imaging of the grain boundaries in the commercially pure $\mathrm{Sn}$ solidified on the graphite surface at $1^{\circ} \mathrm{C} / \mathrm{s}$.

\begin{tabular}{|c|c|c|c|}
\hline $\begin{array}{l}\text { Table III. Grain } \\
\text { misorientations }\end{array}$ & and & twin & boundary \\
\hline Grain Boundary & & Mis & entation $\left({ }^{\circ}\right)$ \\
\hline $\mathrm{A} \rightarrow \mathrm{B}$ & & & 61.8 \\
\hline $\mathrm{A} \rightarrow \mathrm{C}$ & & & 62.1 \\
\hline$A \rightarrow D$ & & & 63.1 \\
\hline $\mathrm{B} \rightarrow \mathrm{C}$ & & & 60.2 \\
\hline $\mathrm{A} \rightarrow \mathrm{E}$ & & & 81.2 \\
\hline $\mathrm{B} \rightarrow \mathrm{D}$ & & & 87.2 \\
\hline $\mathrm{B} \rightarrow \mathrm{E}$ & & & 43.7 \\
\hline
\end{tabular}

The EBSD results are from the commercially pure $\mathrm{Sn}$ sample solidified on graphite at $1{ }^{\circ} \mathrm{C} / \mathrm{s}$ for the boundaries (A-E) indicated in Fig. 10.

prior to twinning that occurred during cooling, as will be discussed later.

The EBSD results of the commercially pure Sn sample solidified on graphite at $1{ }^{\circ} \mathrm{C} / \mathrm{s}$ are shown in Fig. 10, which is the sample that contained a regular array of angular boundaries. The figure on top is an image quality map showing the general microstructure with the high angle boundaries and is similar in appearance to the optical light microscopy image shown in Fig. 9b. The same area was then colored according to the inverse pole figure for each grain orientation, as shown in the lower image. The colors in the orientation map are keyed to the 001110-110 fundamental zone for a tetragonal lattice. Table III summarizes the orientation relationships for the labeled grains (A-E) in Fig. 10. It can be readily seen that numerous sigma-3 $\left(\sim 60^{\circ}\right)$ and $c$-axis $\left(\sim 90^{\circ}\right)$ twin orientations are nucleated within the big grain that is labeled 'A'. Here, it is clear that there are two major grain orientations, corresponding to the striping of the sample, and a third orientation which traverses the stripes in two locations. The predominance of the two major orientations throughout the entire cross-section of the sample indicates that the sample most likely solidified as a single grain, which was later transformed into the two dominant twinned grain orientations.
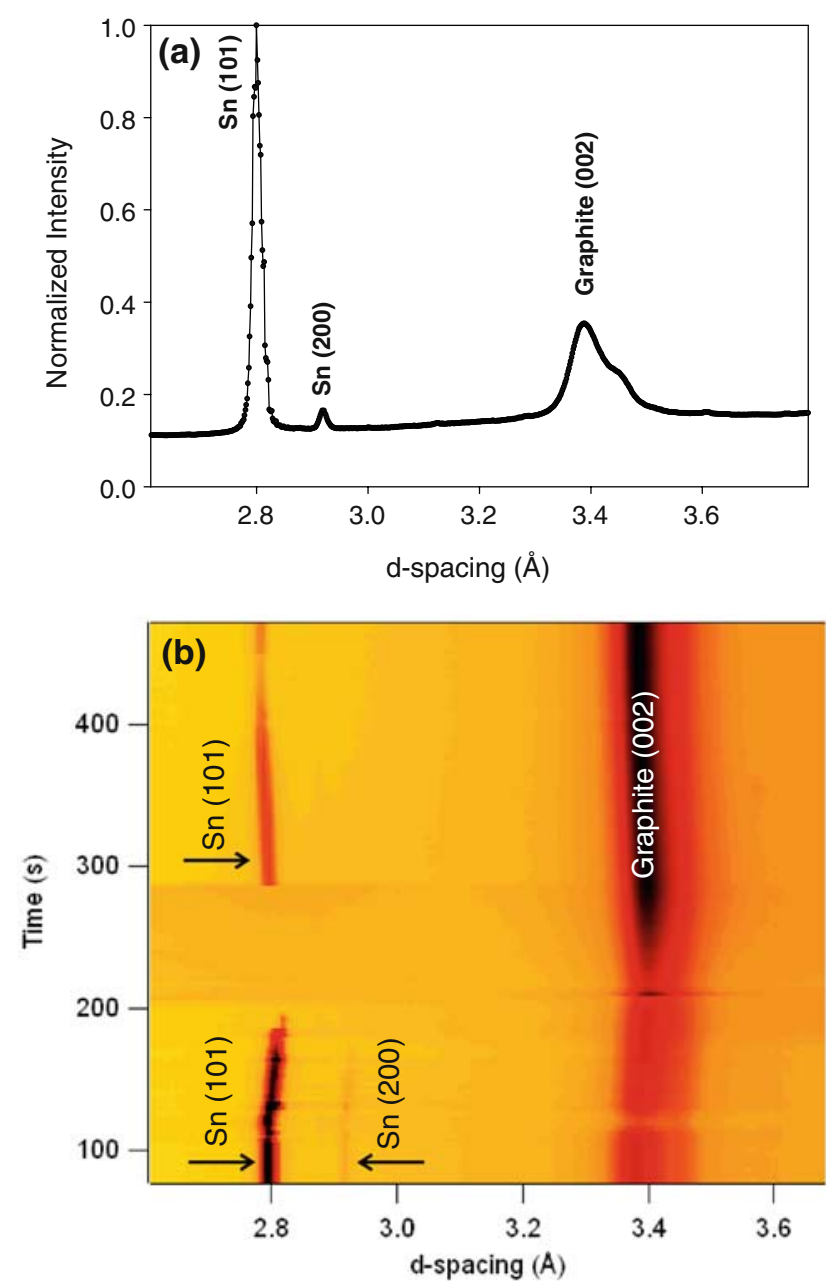

Fig. 11. (a) Initial diffraction peaks of the commercially pure $\mathrm{Sn}$ sample on graphite, prior to heating and cooling at $1{ }^{\circ} \mathrm{C} / \mathrm{s}$. (b) In situ $\mathrm{x}$-ray diffraction patterns for heating that begins at $t=105 \mathrm{~s}$, melting that occurs at $t=204 \mathrm{~s}$, and solidification that begins at $t=286 \mathrm{~s}$. Note that the Sn (101) peak appears on solidification, while the Sn (200) is absent.

A misorientation angle of approximately $60^{\circ}$ is a common twinning angle for $\mathrm{Sn},{ }^{21}$ and the EBSD results show that the four analyzed $60^{\circ}$ boundaries had an average misorientation of $61.8^{\circ}$, which is indicative of (301)[-103] twins rotated around the [010] axis. $^{22}$

The commercially pure Sn sample that was most heavily twinned was analyzed in further detail to enable us to determine if any additional information could be gained from the x-ray diffraction patterns that might be an indication of twinning. Figure 11a shows the initial diffraction pattern for this sample, which is textured such that the $\operatorname{Sn}(101)$ is again more intense than the $\operatorname{Sn}(200)$. The corresponding series of diffraction patterns for this sample are shown in Fig. 11b, from the beginning to the end of the experiment. Heating begins at $t=105 \mathrm{~s}$, and the Sn peaks move to higher $d$-spacings as the sample heats up. Melting occurs at $t=204 \mathrm{~s}$, and the 

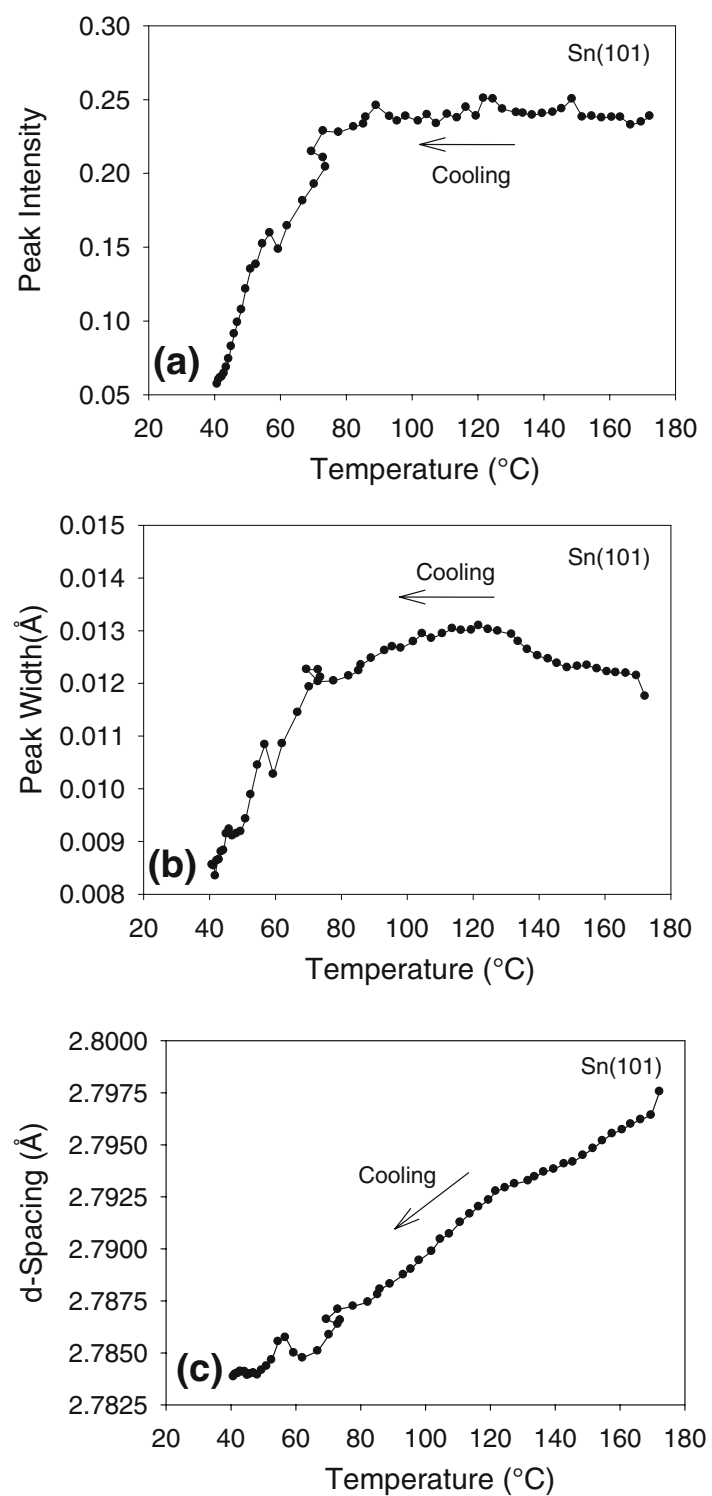

Fig. 12. (a) peak intensity, (b) peak width, and (c) $d$-spacing of the $\mathrm{Sn}$ (101) peak during cooling of the commercially pure $\mathrm{Sn}$ that cooled at $1^{\circ} \mathrm{C} / \mathrm{s}$ and was heavily twinned.

sample shows only diffraction from the graphite sample holder until $t=286 \mathrm{~s}$, where solidification occurs and the Sn(101) peak appears. The temperature at this point is $172^{\circ} \mathrm{C}$, and the $\mathrm{Sn}$ (101) peak remains to room temperature.

We performed individual peak analysis on these data by measuring the intensity, width, and $d$-spacing of the Sn (101) peak after solidification had occurred. These results are presented in Fig. 12, which indicate that both the peak intensity and the peak width experienced a sharp decrease at approximately $80^{\circ} \mathrm{C}$, while the $d$-spacing of the $\mathrm{Sn}$ (101) peak continued its approximate linear decreasing trend with temperature. From the slope of the $d$-spacing versus temperature plot (Fig. 12c), the contraction of $\mathrm{Sn}$ (101) planes was determined to be $37.0 \times 10^{-6} /{ }^{\circ} \mathrm{C}$, based on a linear fit through the data. This value was close to the reported value for $\beta$-Sn (101) of $27.6 \times 10^{-6} /{ }^{\circ} \mathrm{C}$ at $30^{\circ} \mathrm{C}$ and $37.6 \times 10^{-6} /{ }^{\circ} \mathrm{C}$ at $150^{\circ} \mathrm{C}$. ${ }^{23}$ The linear trend of the measured coefficient of thermal expansion (CTE) during cooling of this sample suggested that there was no phase change at $80^{\circ} \mathrm{C}$ that would have been responsible for the changes in peak intensity and peak width. This further suggested that the twinning was probably responsible for the observed changes in x-ray diffraction peak character at approximately $80^{\circ} \mathrm{C}$, since $\beta$-Sn would have remained after twinning. The decrease in peak width would have indicated that microstrains were building up in the resolidified Sn disk during cooling to $80^{\circ} \mathrm{C}$ were being relieved by twinning and were producing more narrow diffraction peaks. In addition, the formation of newly twinned grains with different crystallographic orientations was likely contributing to the decrease in the overall observed peak intensity.

\section{High Purity Sn on Copper Substrates}

High purity Sn was melted and solidified on a $\mathrm{Cu}$ substrate to enable us to see how the Sn reaction with the substrate affected the microstructure and undercooling. Since Sn and copper form a eutectic at $227^{\circ} \mathrm{C}$, the tin should have started to react with the $\mathrm{Cu}$ substrate at this temperature, which is below the melting point of Sn. Table II summarizes the results of three runs where high purity $\mathrm{Sn}$ was melted with a heating rate of $2{ }^{\circ} \mathrm{C} / \mathrm{s}$ and solidified on the $\mathrm{Cu}$ substrate at cooling rates of $4{ }^{\circ} \mathrm{C} / \mathrm{s}, 0.5^{\circ} \mathrm{C} / \mathrm{s}$, and $0.05{ }^{\circ} \mathrm{C} / \mathrm{s}$. The measured melting points were, indeed, lower than the melting point of pure Sn, averaging $221^{\circ} \mathrm{C}$ and indicating that the $\mathrm{Sn}$ was reacting with the $\mathrm{Cu}$ substrate as expected, within the expected accuracy of the temperature measurements. These samples also displayed undercooling prior to solidification during cooling, where the amount of undercooling varied from $22^{\circ} \mathrm{C}$ to $30^{\circ} \mathrm{C}$ but, again, having no obvious trend with cooling rate. These data are summarized in Table II and show an average undercooling of $26^{\circ} \mathrm{C}$ below the $\mathrm{Sn}-\mathrm{Cu}$ eutectic of $227^{\circ} \mathrm{C}$. This amount of undercooling was within the range of $20-26^{\circ} \mathrm{C}$ recently reported for DSC measurements of Sn solidified on a $\mathrm{Cu}$ substrate. ${ }^{7}$

The microstructure of the Sn melted on $\mathrm{Cu}$ was quite different from that melted on graphite, due to dissolution of the $\mathrm{Cu}$ in liquid $\mathrm{Sn}$. Figure 13 shows a cross-section through one of the samples that was cooled at a rate of $0.5^{\circ} \mathrm{C} / \mathrm{s}$, showing the intermetallic layer that formed between the $\mathrm{Cu}$ and the Sn. Occasional second-phase particles appeared in the matrix and were approximately $3 \mu \mathrm{m}$ in size. These particles were presumably $\mathrm{Cu}_{6} \mathrm{Sn}_{5}$, which forms during the solidification of the eutectic microconstituent that occurs in 99.3 wt.\% Sn. ${ }^{24}$ The intermetallic layer that formed between the $\mathrm{Cu}$ and the Sn had a scalloped appearance, characteristic of 


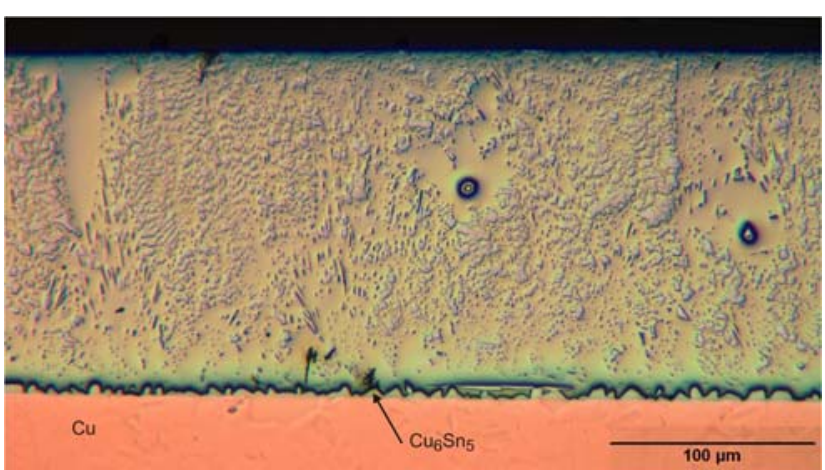

Fig. 13. High purity Sn melted and solidified on a copper substrate. The low cooling rate of this sample of $0.5^{\circ} \mathrm{C} / \mathrm{s}$ allowed ample time for the liquid $\mathrm{Sn}$ to react with the Cu substrate.

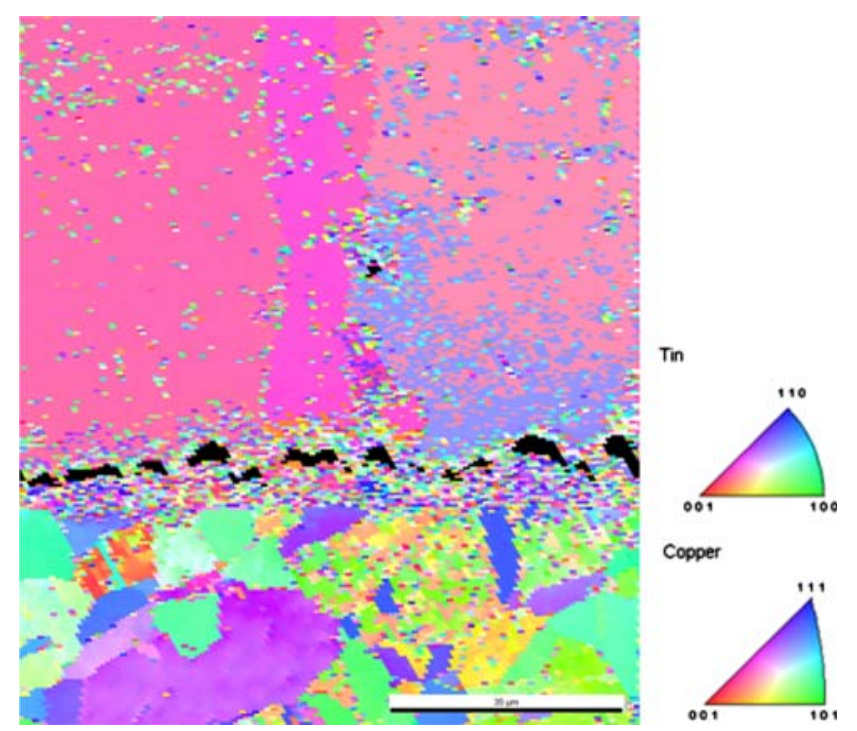

Fig. 14. Results from EBSD imaging of high purity Sn solidified on the Cu substrate. The Cu substrate is located in the lower portion of the figure, and the reflowed $\mathrm{Sn}$ is in the upper portion of the figure.

the $\mathrm{Cu}_{6} \mathrm{Sn}_{5}$ phase, ${ }^{25}$ and was $\sim 7 \mu \mathrm{m}$ thick. The thickness of this layer was the direct result of the long time ( $\sim 2 \mathrm{~min})$ that the liquid $\mathrm{Sn}$ was in contact with the $\mathrm{Cu}$ substrate at the slow cooling rate of $0.5{ }^{\circ} \mathrm{C} / \mathrm{s}$ for this sample.

EBSD imaging was further performed on the high purity Sn sample solidified on the copper substrate. Figure 14 shows the EBSD results near the center of the optical micrograph shown in Fig. 13. In the EBSD results shown in Fig. 14 the copper substrate is located in the lower half of the image and the reflowed $\mathrm{Sn}$ is on top. The EBSD map of the copper grains indicates the presence of large-angle grain boundaries, with average grain sizes on the order of $10 \mu \mathrm{m}$. The interface between the $\mathrm{Cu}$ and the Sn shows up as a band approximately $10 \mu \mathrm{m}$ wide with an irregular structure surrounding the $\mathrm{Cu}_{6} \mathrm{Sn}_{5}$ intermetallic phase (black shading). The reflowed Sn reacted with the copper substrate to form a large fraction eutectic constituent composed of $\mathrm{Sn}$ and $\mathrm{Cu}_{6} \mathrm{Sn}_{5}$ phases. The presence of the eutectic constituent resulted in the mottled appearance of the EBSD pattern as the different phases of the eutectic were probed by the beam. Longer vertical boundaries were also present, indicating that the $\mathrm{Sn}-\mathrm{Cu}$ alloy had solidified with columnar grains oriented approximately perpendicular to the $\mathrm{Cu}$ substrate surface. The results of these EBSD observations indicated that the $\mathrm{Sn}$ reflowed on the $\mathrm{Cu}$ substrate had formed a significantly different microstructure from that of the Sn solidified on graphite, with a microstructure consisting of a large fraction of eutectic microconstituent, columnar grains and no twins. This microstructure formed with less undercooling than the Sn solidified on graphite and would be expected to have significantly different properties from those of the Sn solidified on graphite.

\section{CONCLUSIONS}

In situ x-ray diffraction patterns of the Sn that was melted and solidified on a non-reacting graphite substrate showed undercoolings as high as $61^{\circ} \mathrm{C}$. Differences in the purity of the Sn produced substantially different undercoolings, with less pure $\mathrm{Sn}$ exhibiting higher undercoolings $\left(\Delta T=55^{\circ} \mathrm{C}\right)$ than high purity $\mathrm{Sn}\left(\Delta T=20^{\circ} \mathrm{C}\right)$. However, due to the statistical nature of $\beta$-phase nucleation during undercooling, more samples need to be tested to confirm these results. Optical metallographic examination and EBSD performed on the undercooled Sn samples on graphite surfaces showed that the Sn solidified with very few grains in the microstructure. The high purity Sn sample had large grains with wavy boundaries and was free of twins, while the commercial purity Sn samples solidified with only one grain and contained twins with a predominant twinning angle of $61.8^{\circ}$. Twinning of the commercial purity Sn samples was considerably more prominent in the sample more rapidly cooled at $1{ }^{\circ} \mathrm{C} / \mathrm{s}$. In situ x-ray diffraction showed a dramatic decrease in the peak width and intensity at $80^{\circ} \mathrm{C}$ that was attributed to twinning that occurred during cooling of this sample. When solidified on a $\mathrm{Cu}$ substrate, the $\mathrm{Sn}$ samples melted near the $\mathrm{Cu}-\mathrm{Sn}$ eutectic of $227^{\circ} \mathrm{C}$ and solidified with less undercooling $\left(\Delta T=26^{\circ} \mathrm{C}\right)$ than on graphite. The microstructure consisted of a eutectic $\mathrm{Sn}+\mathrm{Cu}_{6} \mathrm{Sn}_{5}$ phase, primary Sn dendrites, and occasional secondphase particles. This microstructure was irregular and highly refined in a $10 \mu \mathrm{m}$ band about the $\mathrm{Cu} / \mathrm{Sn}$ interface. We have shown that in situ x-ray diffraction can measure the large undercooling which results in a microstructure that is largely unsuitable for soldering applications. Future work will analyze the effects of compositional modifications on this undercooling so that we can understand the mechanisms by which soldering behavior may be improved. 


\section{ACKNOWLEDGEMENTS}

The authors would like to thank Mr. Jackson Go of the Lawrence Livermore National Laboratory (LLNL) for performing the optical metallography, Mr. Edwin Sedillo of LLNL for performing the SEM and EBSD characterization, Mr. Mike Santella of Oak Ridge National Laboratory (ORNL) for assisting with the $\mathrm{x}$-ray diffraction analysis software, and Jenia Karapetrova of the APS for assisting with the synchrotron beam-line setup and operation. This work was performed under the auspices of the U.S. Department of Energy by Lawrence Livermore National Laboratory under contract DE-AC5207NA27344 and by Oak Ridge National Laboratory under contract DE-AC05-00OR22725. Much of this work was supported by the Department of Energy (DOE), Office of Basic Energy Sciences, Division of Materials Science and Engineering. In situ experiments were performed on 34-BM-C at the APS, which is supported by the U.S. DOE, Basic Energy Sciences, Office of Science under contract no. W-31-109-ENG-38.

\section{OPEN ACCESS}

This article is distributed under the terms of the Creative Commons Attribution Noncommercial License which permits any noncommercial use, distribution, and reproduction in any medium, provided the original author(s) and source are credited.

\section{REFERENCES}

1. P.T. Vianco, Weld. J. 86, 27 (2007).

2. P. Baskin, Weld. J. 86, 58 (2007).

3. K.J. Puttlitz, Handbook of Lead-Free Solder Technology for Microelectronic Assemblies, ed. by K.J. Puttlitz and K.A. Stalter (New York: Marcel Dekker, 2004).

4. J.H. Perepezko, Mater. Sci. Eng. 65, 125 (1984).

5. D. Swenson, J. Mater. Sci.: Mater. Electron. 18, 39 (2007).

6. R. Kinyanjui, L.P. Lehman, L. Zavalij, and E. Cotts, J. Mater. Res. 20, 2914 (2009).
7. Y-C Huang, S-W Chen, and K-S Wu, J. Electron. Mater. Published on-line (10 November 2009).

8. L.P. Lehman, S.N. Athavale, T.Z. Fullem, A.C. Giamis, R.K. Kinyanjui, M. Lowenstein, K. Mather, R. Patel, D. Rae, J. Wang, Y. Xing, L. Zavalij, P. Borgesen, and E.J. Cotts, J. Electron. Mater. 33, 1429 (2004).

9. K.N. Subramanian and J.G. Lee, J. Mater. Sci.: Mater. Electron. 15, 235 (2004).

10. T.R. Bieler, H. Jiang, L.P. Lehman, T. Kirkpatrick, and E.J. Cotts, Proceedings of the 56th Electronic Components and Technology Conference (San Diego, CA, 2006), p. 1462.

11. D.W. Henderson, J.J. Woods, T. Goselin, A. Sarkhel, S.K. Kang, W.-K. Choi, D.-Y. Shih, C. Goldsmith, and K.J. Puttlitz, J. Mater. Res. 19, 1608 (2004).

12. D.W. Henderson, T. Gosselin, A. Sarkhel, S.K. Kang, W.K. Choi, D.Y. Shih, C. Goldsmith, and K.J. Puttlitz, J. Mater. Res. 17, 2775 (2002).

13. A. LaLonde, D. Emelander, J. Jeannette, C. Larson, W. Rietz, D. Swenson, and D.W. Henderson, J. Electron. Mater. 33, 1545 (2004).

14. J.W. Elmer, T.A. Palmer, and E.D. Specht, Metall. Mater. Trans. A 38A, 464 (2007).

15. J.W. Elmer, T.A. Palmer, and E.D. Specht, Mater. Sci. Eng., A 459, 151 (2007).

16. J.W. Elmer, T.A. Palmer, S.S. Babu, and E.D. Specht, Mater. Sci. Eng., A 391, 104 (2005).

17. J.W. Elmer, T.A. Palmer, and E.D. Specht, J. Vac. Sci. Technol., A 24, 978 (2006).

18. J.W. Elmer, T.A. Palmer, S.S. Babu, and E.D. Specht, Scripta Mater. 52, 1056 (2005).

19. A.J. Schwartz, M. Kumar, and B.L. Adams, eds., Electron Backscatter Diffraction in Materials Science (New York: Kluwer Academic/Plenum Publishers, 2000).

20. P. Villars, Pearson's Handbook of Crystallographic Data for Intermetallic Phases, desk edition, Vol. 2 (Materials Park, Ohio: ASM International, 1997).

21. F. Yang and J.C.M. Li, J. Mater. Sci.: Mater. Electron. 1, 191 (2007).

22. J. Sylvestre and A. Blander, J. Electron. Mater. 37, 1618 (2008).

23. V.T. Deshpande and D.B. Sirdeshmukh, Acta Cryst. 14, 355 (1961).

24. K. Ishida and T. Nishizawa, Binary Alloy Phase Diagrams, ed. by T.B. Massalski, 2nd ed., Vol. 2 (Materials Park, OH: ASM International, 1990).

25. J.O. Suh, K.N. Tu, and N. Tamura, J. Appl. Phys. 120, 063511 (2007). 